\title{
INTEGRATING AHP AND DYNAMIC SIMULATION: EXPERIENCES, CONCEPTUALIZATIONS AND BUSINESS EXPERIMENTS
}

\author{
Hannu Kivijärvi and Markku Tuominen \\ Helsinki School of Economics and Business Administration, \\ P.O. Box 1210, 00100 Helsinki, Finland, \\ Lappeenranta University of Technology,P.O. Box 20, 53851 Lappeenranta, Finland \\ Hannu.Kivijarvi@hkkk.fi / Markku.Tuominen@lut.fi
}

\begin{abstract}
In this paper we first summarize shortly our long experience in integrating Analytic Hierarchy Processes to the dynamic simulation of business systems. Then we show by an actual production-distribution case the obvious benefits of the integrative approach. Productiondistribution systems are related to most functions within the firm, beginning from the materials management and ending with deliveries to markets. In such a case, the complex, direct and indirect relationships imply that the straightforward, traditional evaluation techniques do not necessarily lead to the best result. We cannot convert every intangible effect into monetary gains or expenses. In addition, we also have to use such criteria as flexibility, material availability, product quality, system stability, etc. In this research we show how an integrated simulationevaluation system can support the management of intangible production-distribution systems in an efficient manner.
\end{abstract}

\section{Introduction}

Most simulation languages and other process modeling systems do not support to investigate multiple, conflicting goals and their relationships. Here the simulation refers to an artificial method whereby the time-related outputs are calculated from the values of input variables by taking into account the relationships between those two sets of variables. Typically the simulation systems concentrate only on the procedural characteristics of the problem in question. On the other hand, Analytic Hierarchy Process (AHP) is a powerful device to analyze specially the goal structure of a particular problem situation, but it has no capabilities to analyze the dynamics of a problem situation.

In practice, however, most decision situations involve both features; goal structures and dynamics. It is typical that decision situations involve a number of people with numerous goals and objectives, and the time frame of the problems covers even years. In order to analyze the dynamic behavior and goal structure of a particular system or problem we need to integrate AHP with a simulation system. Such an integration is an extremely useful concept in all decision situations where time is an important factor and goals are conflicting with each other.

As a descriptive example we analyze the investment decisions in a production-distribution case. New methods and technologies (EDI, Internet) have changed dramatically the ways in which firms manage their operations and their relations with customers. The production-distribution systems are at the center of these changes. The need of high quality and high efficiency has become characteristics of new logistics systems. One of the main problems with the production-distribution management is the issue of investment decisions. Because the logistics systems are highly related to most functions within the firm beginning from the materials management and ending with marketing they have also a lot of direct and indirect effects on the operation of the firm. These complicated interrelations imply that we cannot use only straightforward, traditional techniques of investment analyses. We cannot convert every outcome into monetary incomes or expenses. In addition, we also have to use such criteria as flexibility, material availability, product quality, system stability, etc. 
In this paper we first summarize our experience over the last 10 years of such research projects where dynamic results of simulations are evaluated by using AHP. Then we show by a production-distribution case the typical procedure of the integrative approach and its obvious advantages and possible problems.

\section{Former experiences in integration of simulation and AHP}

Under the management of the authors of this paper a number of research projects are conducted where a dynamic business model is integrated to an evaluation procedure as established by AHP. Our professional background builds on Management Science in business and industrial engineering. It became obvious during the first joint research projects in the late eighties that the results of the simulations are very complex to evaluate. The joint projects between a business school and a university of technology concerned mainly strategic business issues where the long time horizon was incorporated with a complex set of values and other preferences. Then, it was natural to integrate AHP with some process-modeling tools.

During the last 10 years over twenty articles or other research reports were published by us concerning the joint utilisation of simulation and AHP. In Table 1 some of the most significant reports with application areas of the main projects are summarised.

\begin{tabular}{|l|l|l|}
\hline Reference & \multicolumn{1}{|c|}{ Year } & \multicolumn{1}{c|}{ Application Area } \\
\hline$[4],[5]$ & 1988,1989 & Production and Financial Strategies \\
\hline$[6],[7]$ & 1989,1991 & Logistics Management \\
\hline$[8],[14]$ & 1992,1999 & Executive Information Systems (EIS) \\
\hline$[8],[9],[3]$ & $1992,1993,1996$ & Evaluation of Intangible Investments \\
\hline$[11],[12]$ & 1997 & ODSS in Strategic Planning \\
\hline$[10]$ & 1996 & Strategic Planning and Analysis \\
\hline$[13]$ & 1998 & Strategic Investments \\
\hline
\end{tabular}

Table 1. Integrating simulation and AHP: application areas

In those projects a number of methods are used. Because the problem areas have generally been quite wide (strategic) we have extensively adopted a systems approach to model the problems. Specially, the System Dynamics concepts have been frequently exploited. As a simulation language we have used Dysmap2, Professional Dynamo, or Ithink software. In some cases Excel is used. In order to build the AHP evaluation hierarchies Expert Choice and Logical Decisions for Windows are used. Quite recently we have worked with a project were the goals, objectives, and strategies of a large wood-processing company are created, analyzed and evaluated by a support system where a corporate-wide simulation model, group support system, and AHP are used simultaneously.

Recently, on the basis of literature search, we have found two papers [1], [2] reporting about the similar combinations of simulation and AHP (or ANP). This may indicate that there exists a greater need to evaluate consistently the organizational goals and objectives that are linked to the network of business processes.

Our experience highlights some obvious advantages of the integrative approach. From the simulation point of view, AHP is a method that directs the development of the simulation model. During the development process it is possible to determine by AHP the variables to be included into the model. The essential criteria and their relative weights can then be used as a starting point in formulating the simulation model formulation phase, too. In this way the problems restriction and variable selection are tied to the original problems and the goals, and objectives of the firm. Perhaps the most important advantage is that AHP helps to find the efficient solution in simulation context. On the other hand, from AHP point of view, 
simulation provides long-felt dynamics to the static evaluation procedure. Typically, AHP evaluations are based only on subjective assessments. Simulation moves the evaluation toward a more factual basis. It is possible to utilize quantitative calculations behind the evaluations. Also, when we describe and simulate the dynamic behavior of a network of complicated business processes we have established a more stable ground to evaluate the independence or dependence of the decision criteria.

In next section we concentrate on the production-distribution problem. By this problem we show the primary principles of the integration and its advantages.

\section{Production-distribution issue}

Production-distribution systems are cross-functional systems. They affect all major functions or departments within the company beginning from the raw material deliveries and ending with the deliveries of finished goods. Therefore, the production-distribution systems are critical for the success of a function or a department and further for the success of the whole company. New technologies (EDI, Internet) have changed dramatically the way in which companies manage their operations and their relations with customers. The production-distribution systems are in the hearth of many of these changes. The need of high quality and high efficiency has become characteristics of the new productiondistribution systems.

Because the horizontal production-distribution systems are a. vital part of the overall corporate strategy there is also a good reason to evaluate the proposed system alternatives multidimensionally. The logistic processes run through a number of functions and departments within a firm. Therefore we need a set of measures to describe the performance of each related activity.

\section{Case description}

In this section we shortly describe a case which is later used in demonstrative experiments. Although we describe our approach with an actual case we remind that the approach is by no means limited to this particular case but can be applied to the management of intangible investments in general.

Our case, which describes the logistics system of a real firm, is described in details in [1989]. The reader interested in the details is urged to turn to the original source. The case-company manufactures and markets high-quality goods. It markets the products in the home markets and foreign markets within and beyond Europe. Organizationally the firm is divided into three related companies. The basic demand for a product follows the typical product life cycle. On the average, the marketable life of a product is about one year. From experience it is known that the inventories at sales companies fluctuate widely, sometimes the sales companies are even out of stock. Production planning at the head office is also difficult because of the sharp variations in the quantities ordered.

The independent dealers who retail the products have inventories for four weeks' sales. They order the products from local sales companies that deliver the ordered products if they have them. The desired inventory at sales-companies covers the sales of eight weeks. At the beginning of each month the sales companies forecast their sales to the dealers, and inventory positions for each of the six forthcoming months. This information is submitted to the head office for actual production planning, production, and delivery.

In the case-company there are several potential strategies to improve the present production-distribution system. One way to decrease the distribution costs is to decrease the inventories at sales companies. Another decision alternative is to increase the inventories in order to moderate the perceived production fluctuations. Possibly, the dealers could be motivated to keep higher inventory levels by a more effective pricing policy.

In addition to these modifications of the present system it is possible to build a totally new productiondistribution system. The primary features of the proposed new system are: The factory would hold an inventory of finished goods, the production program would be that this inventory is kept at a given level, the 
sales companies would hold inventories in the few strategically located distribution centers, and the dealer would have low inventories for immediate sales only.

It is assumed that the new system would be more stable and easier to control. Of course, there would be a lot of potential alternatives for desired inventories, production targets, lengths of decision periods, demand forecasts, etc.

\section{Criteria formulation}

As mentioned above, the analytic hierarchy process (AHP) is used to select the decision criteria. AHP is a general decision-making tool (generator) that can be used to evaluate complex multiattribute alternatives, which may include subjective or intangible criteria [15]. AHP can assist decision makers in obtaining a detailed understanding of how the preference judgements concerning the relative importance of attributes influence their choice decision.

AHP involves decomposing a decision problem into subproblems in a hierarchical fashion that can be comprehended and evaluated, determining the priorities of the elements at each level of the decision hierarchy, and synthesizing the priorities to determine the overall priorities of the decision alternatives.

In Figure 1, the whole analytic hierarchy process for the evaluation of the production-distribution systems is illustrated. At the top of the hierarchy lies the most general objective of a decision problem. The lower level of the hierarchy contains criteria such as sales, cash flow, stability, controllability etc. The last level of the hierarchy contains decision alternatives, i.e., system alternatives.

A comparison of the elements in pairs at this level produces the order of relative importance with respect to the highest goal, Figure 3. We see that cumulative net cash flow is the most important, representing $27.6 \%$ of the total, and distribution costs per unit and production costs per unit is the least important with $6.5 \%$ of the total.

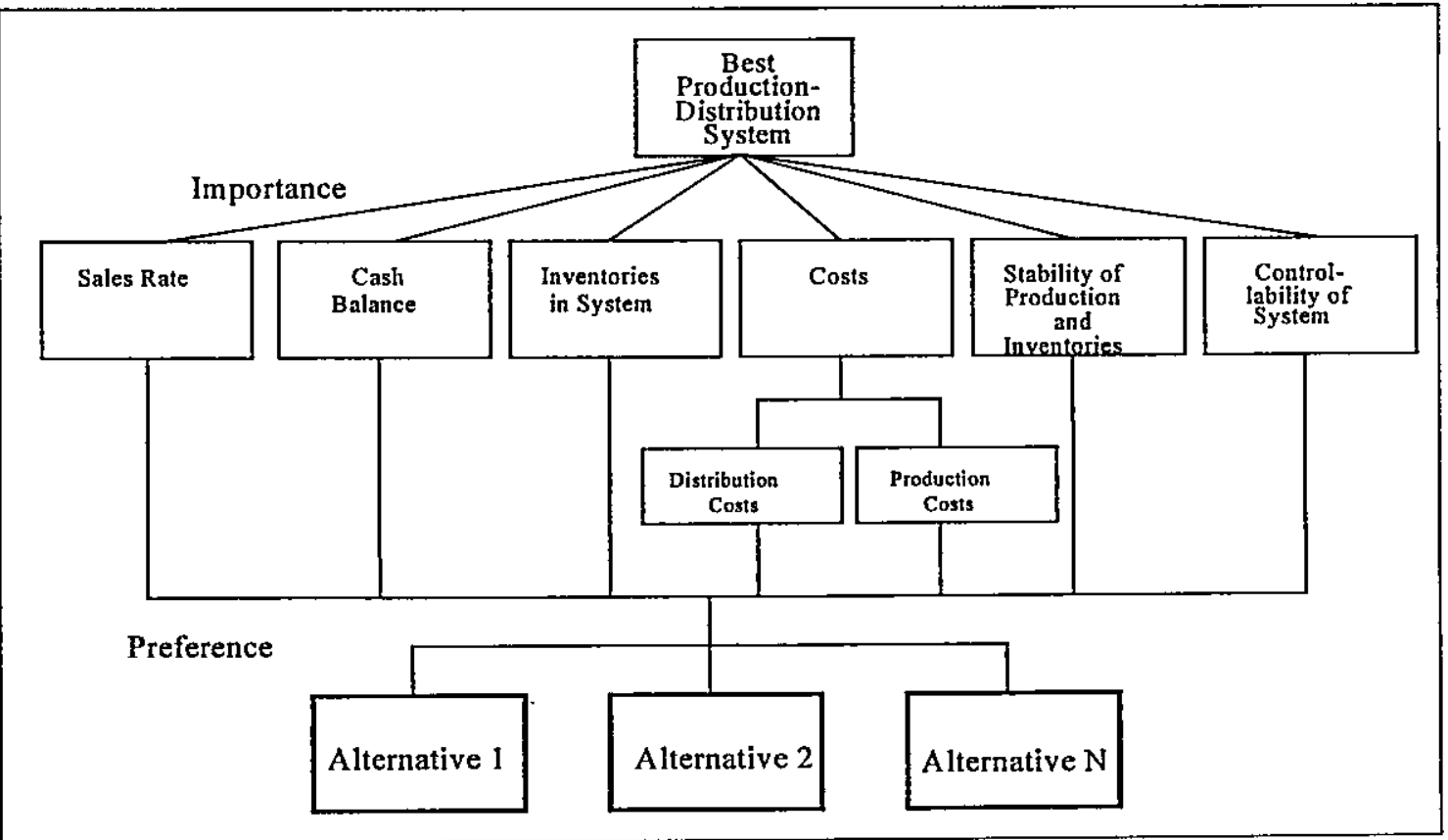

Figure 1. Criteria formulation and hierarchy 


\section{Dynamic simulations}

The original model is programmed in Professorial Dynamo simulation language, and it includes about 90 variables, constants, and tables. The model is divided into four sectors: Market Demand, Dealers order generation, Forecasting, and Production Planning. In order to analyze the financial effects of possible strategies we have added the fifth sector into the model: Financial sector. For the demonstrative computations we selected only the following three decision alternatives from the whole set of alternatives:

Alternative I: Present system (Status Quo)

Alternative lI: Inventory reduction system

Alternative III: New production distribution system

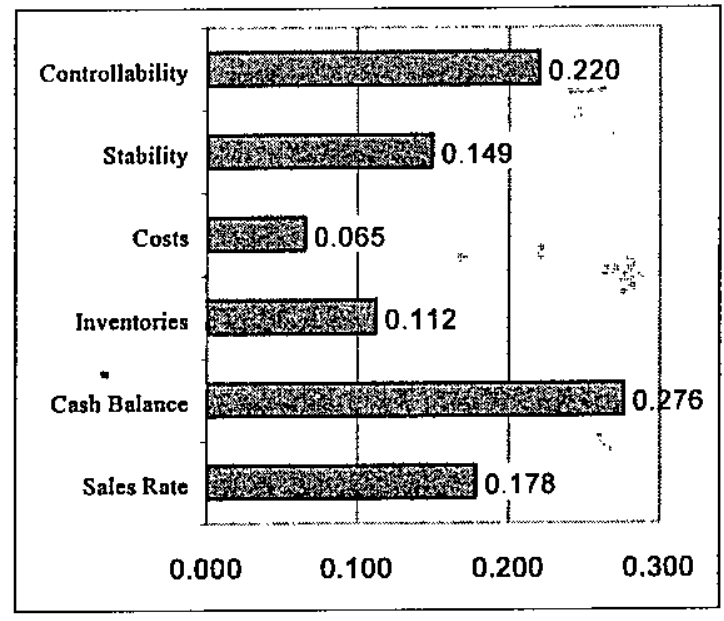

Figure 2. Priorities of the criteria

The graphic results of the respective one decision alternative are presented in Figure 3 . The simulation period is six years which covers three product life cycles. In the present system every demand is met and there are no lost sales. Unfortunately, the fluctuations in the inventories and in the production level are severe. The variations in the production level have a direct impact on the production costs and further on the cash flow, too. Because one vital part of the system, the dealer inventories, cannot be controlled by the managers, the controllability of the present system is not satisfactory.

The situation is even worse when the inventories are reduced from 8 weeks to cover one month. Sales are lost and the fluctuations are not decreased. It is interesting to note that the sales are lost after the highest demand. However, the net cash flow is higher due to the reduced inventory costs (included in the distribution costs). The new logistics system seems to be relatively steady. The inventory levels vary quite reasonably between 400 - 800 units and there are no lost sales. Unfortunately, the initial investment costs are high and consequently the net cash flow remains at a lower level. Every essential element of the system is under the control of the company.

The results of these three potential decision altematives are only illustrative examples of the potential alternatives. In the real life, more alternatives with various combinations could be generated and analyzed. Because there is no such alternative superior to all other alternatives, the final selection is not easy. We must be able to weigh, to give priorities to the goal variables. In the next section such a procedure is described.

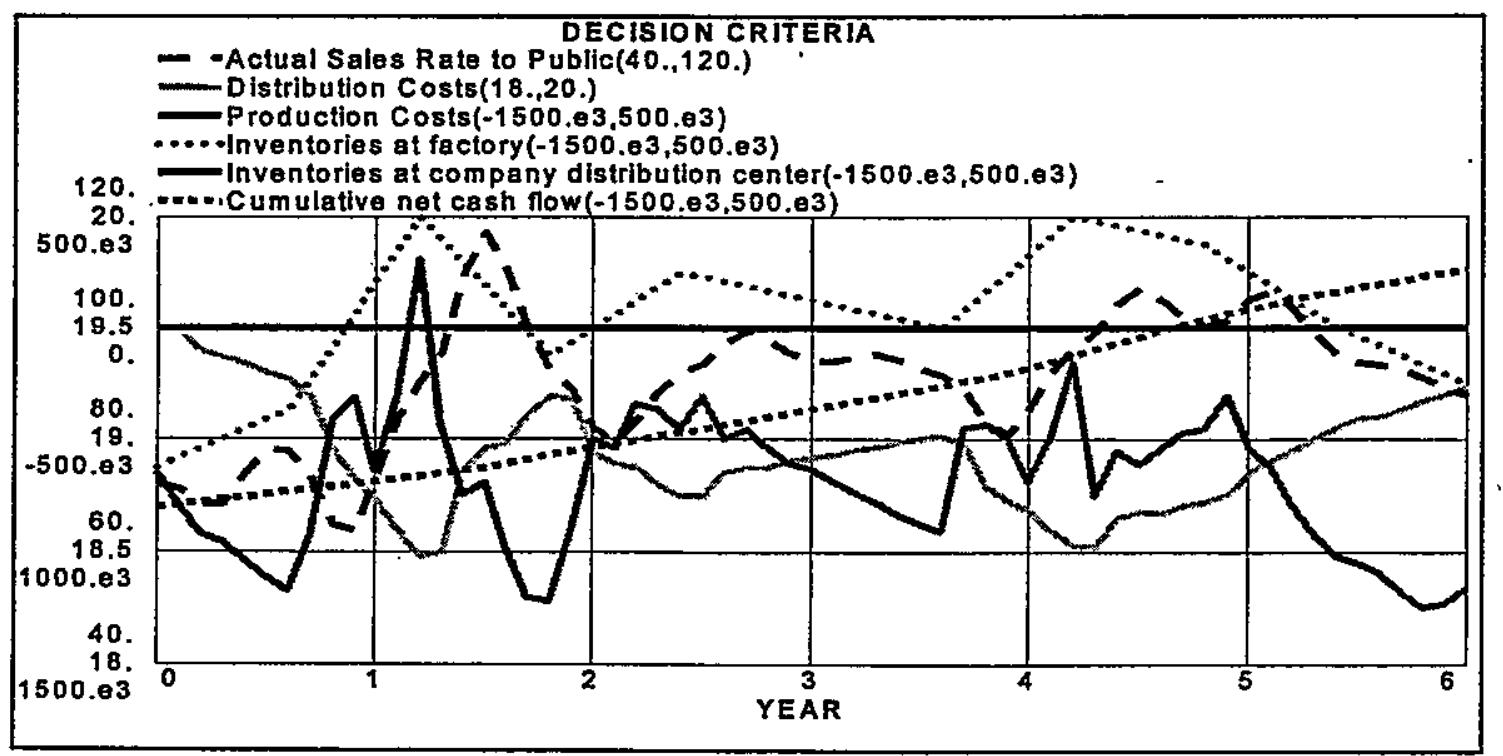

Figure 3. Results of one decision alternative 


\section{Evaluation of simulation results}

In the earlier phase we have used the order of importance of the criteria. Next, we compared the decision alternatives with respect to each criterion. For example, in Figure 4 we judge whether the present system or the reduced inventory system is more preferable with respect to the distribution costs criterion and how much preferable it is. After making all other comparisons in pairs, AHP calculates the results. The total utilities of decision alternatives are synthesized in Figure 5. The new production-distribution system is the best decision alternative with respect to the criteria mentioned above.
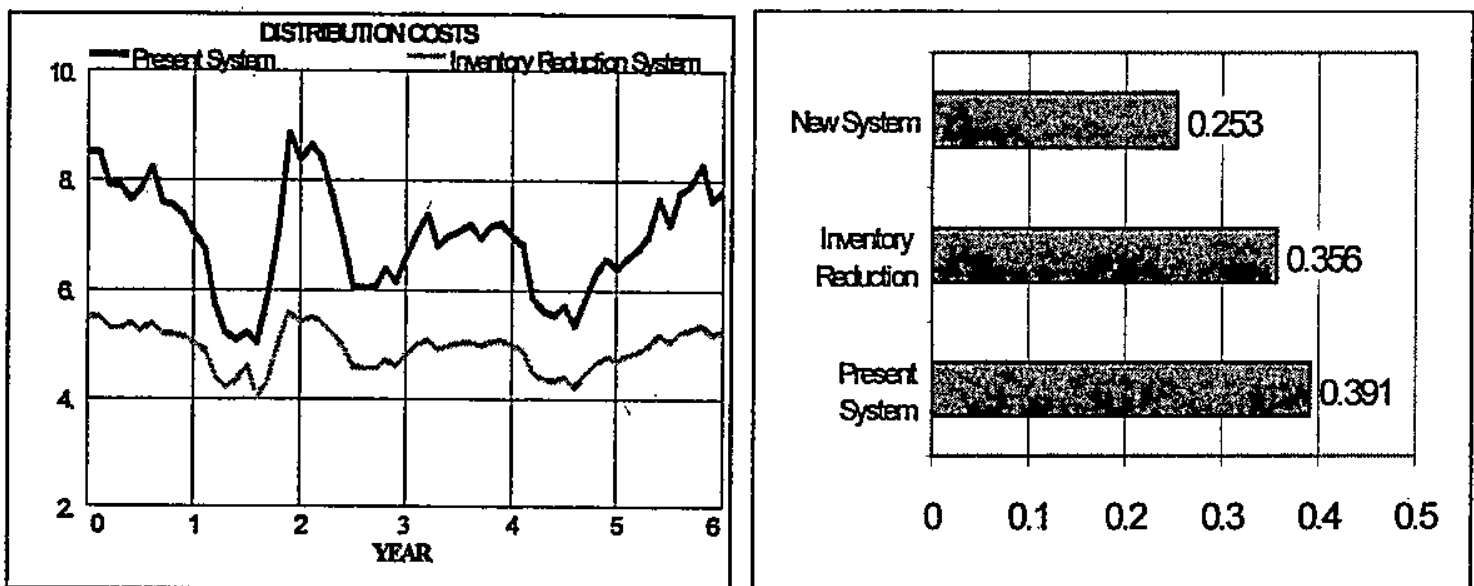

Figure 4.Comparison of two alternatives with respect Figure 5. Utilities of the system alternatives to distribution cost criterion

\section{Conclusion}

Our experiences emphasize some obvious advantages of the simulation and AHP. From the simulation point of view, AHP is a method that directs the development of the simulation model. During the development process it is possible to determine by AHP the variables to be included into the model. The essential criteria and their relative weights can then be used as a starting point in formulating the simulation model formulation phase, too. In this way the problems restriction and variable selection are tied to the original problems and the goals, and objectives of the firm. Perhaps the most important advantage is that AHP helps to find the efficient solution in simulation context. On the other hand, from AHP point of view, simulation provides long-felt dynamics to the static evaluation procedure. Typically, AHP evaluations are based only on subjective assessments. Simulation moves the evaluation toward a more factual basis. It is possible to utilise quantitative calculations behind the evaluations. Also, when we describe and simulate the dynamic behavior of a network of complicated business processes we have established a more stable ground to evaluate the independence or dependence of the decision criteria. In the demonstrative case it was highlighted that the production-distribution systems are complex, cross-functional systems that affect all major functions or departments within the firm beginning from the raw material deliveries and ending with the deliveries of finished goods. An industrial firm has several alternatives for increasing the performance of the logistics operations Consequently, the investments in the logistics systems should be strategically justified, not only cost-justified. The cross-functional effects imply that the investment analysis concerning the whole system must be fulfilled under multiple, diversified criteria 


\section{References}

[1] Ashayeri, J., Kleij, R. and Bröker, A. (1998), "Global business process re-engineering: a system dynamics-based approach", International Journal of Operations \& Production Management, Vol. 18, No $9 / 10,817-831$

[2] Hahm, J. and Lee, M.W. (1994), "A Systematic Approach to Business Process Engineering", Computers and Industrial Engineering, Nos 1-4, 327-330

[3] Keski-Äijö,O., Kivijärvi, H. and Tuominen, M. (1996), Decision Support for Managing Intangible Investments: A Two-Phased Approach, Research Report No. 90, Lappeenranta University of Technology

[4] Kivijärvi, H. and Tuominen, M. (1988), Computerized Financial Planning and Strategic Analysis in an Industrial Firm, Research Report No. 2, Lappeenranta University of Technology

[5] Kivijärvi, H. and Tuominen, M. (1989), "Computer-Based Multi-Attribute Simulation of Production and Financial Strategies", Engineering Costs and Production Economics, Vol. 17, 331-341

[6] Kivijärvi, H. and Tuominen, M. (1989), Investment Justification in Logistics Systems, Lappeenranta University of Technology, Research Report 16

[7] Kivijärvi, H. and Tuominen, M. (1991), "Logistics Management: A Method for Evaluation of Production-Distribution Investments", International Journal of Production Economics, Vol. 24, Nos. 1$2,115-128$

[8] Kivijärvi, H. and Tuominen, M. (1992), A Decision Support System for Semistructured Strategic Decisions: A Multi-Tool Method for Evaluating Intangible Investments, Journal of Decision Systems, Vol. 1, No. 4, 353-376

[9] Kivijărvi, H. and Tuominen, M. (1993), "A Decision Support System for Evaluating Intangible Investments", Computers and Industrial Engineering, Vol. 25, Nos. 1-4, 353-356

[10] Kivijärvi, H. and Tuominen, M. (1996), "A Decision Aid in Strategic Planning and Analysis of a Wood-Processing Company", Computers and Industrial Engineering, Vol. 31, No. 1/2, 467 - 470

[11] Kivijärvi, H. and Tuominen, M. (1997), "ODSS in Strategic Financial and Production Planning", Proceedings of the Thirtieth Anmual Hawaii International Conference on System Sciences, edited by Jay F. Nunamaker and Ralph H. Sprague, Vol III, 337-346,

[12] Kivijärvi, H. and Tuominen, M. (1997), "Use of ODSS in Strategic Planning", International Journal of Information and Management Sciences, Vol. 8, No. 1, 1- 18

[13] Kivijärvi, H. and Tuominen, M. (1998), "Decision Support for Managing Strategic Investments", The Proceedings of the 1998 International Conference on Industry, Engineering, and Management Systems, edited by Edward $\mathrm{H}$. Hernandez, 338-343

[14] Kivijarrvi, H. and Tuominen, M. (1999), "Computer Based Intelligence, Design, Choice, Implementation, and Control of Intangible Investments Projects", Proceedings of the Thirty-Second Annual Hawaii International Conference on System Sciences, (CD-ROM)

[15] Saaty, T.L. (1999), Decision Making for Leaders, RWS Publications, Pittsburgh, PA, 